\title{
Urgences
}

\section{" Épouse et mère "...}

\section{Hélène Carle}

Numéro 5, 3e trimestre 1982

URI : https://id.erudit.org/iderudit/025079ar

DOI : https://doi.org/10.7202/025079ar

Aller au sommaire du numéro

Éditeur(s)

Urgences

ISSN

0226-9554 (imprimé)

1927-3924 (numérique)

Découvrir la revue

Citer ce document

Carle, H. (1982). " Épouse et mère "... Urgences, (5), 67-71.

https://doi.org/10.7202/025079ar

Ce document est protégé par la loi sur le droit d'auteur. L'utilisation des services d'Érudit (y compris la reproduction) est assujettie à sa politique d'utilisation que vous pouvez consulter en ligne.

https://apropos.erudit.org/fr/usagers/politique-dutilisation/
Cet article est diffusé et préservé par Érudit.

Érudit est un consortium interuniversitaire sans but lucratif composé de l'Université de Montréal, l'Université Laval et l'Université du Québec à Montréal. Il a pour mission la promotion et la valorisation de la recherche. https://www.erudit.org/fr/ 
HÉLÈNE CARLE 


\section{"ÉPOUSE ET MĖRE"...}

- Bon, y'est encore sorti. Pis, comme d'habitude, y rentrera probablement pas coucher.

Mon prince charmant! Le lendemain des noces, y'a accroché son chapeau à plumes pis son beau grand manteau d'v'lours. Ça y disait pu d'jouer. Y'a enfilé son costume de "vrai mâle", avec son sourire satisfait, comme on enfile ses vieilles pantoufles. Confortable.

Mais moé j'étais mal. Moé j'voulais encore jouer, à Cendrillon, Blanche Neige, la Belle au bois dormant, à toutes les princesses qu'on m'avait dit qu'j'étais.

Mais j'étais pas une princesse pantoute moé non plus.

Une fois tout ça r'gardé en face, avalé pis digéré, j'm'étais dit "ça peut marcher pareil". J'ai mis tellement d'eau dans mon vin qu'j'en ai oublié l'goût depuis ben longtemps.

J'me suis r'trouvée, ben vite, mariée à un courant d'air, comme on dit, un fantôme. Le fantôme, avec son gros couteau mal aiguisé, qui a déchiré ma vie, qu'j'y avais r'mis entre les mains, six ans auparavant, comme une belle innocente. Cent vingts personnes pour assister au sacrifice. " $\mathrm{C}$ ' $\mathrm{t}$ 'un beau mariage!

Me v'là assise devant une échancrure de six années de longueur, par soixante-douze mois de largeur. Y m'reste pu qu'à sortir mes aiguilles pis ma technique de $r^{\prime}$ prisage invisible. Du fil à $r^{\prime}$ tordre en perspective!...

Moé Isabelle aux grandes ailes, j'ai perdu mon prestige avec toutes mes rémiges.

Y'était v'nu m'arracher à ma famille, à mes paysages, à tout mon monde, avec sa pelle pointue pleine de belles promesses.

$\mathrm{J}$ 'me suis $\mathrm{r}^{\prime}$ trouvée dans une ville qui était pas la mienne, avec du monde pas comme moé. J'en ai tu eu d'la misère à m'adapter pis à $\mathrm{m}^{\prime}$ faire accepter!

"Moé, Isabelle F., trente ans, déracinée, assassinée." 
L'échec. On l'devine aux premiers signes mais on veut pas y croire. L'orgueil humain! Pis on a toujours été mauvais perdants, nous autres, dans ma famille. Ça nous a pas empêché d'perdre plus souvent qu'à notre tour. On s'habitue pas faut croire. Pis on continue à rouler notre échec et mat en faisant semblant d'pas I'voir. Une boule qui grossit à mesure qu'on avance, comme quand la neige est ben molle pis ben collante. J'me fais penser au scarabée qui s'promène avec sa boulette, même si 'est rendue plus grosse que lui, pis qu'y a toutes les misères du monde à en v'nir à boutte, pis qu'a va finir par l'écraser.

Là, l'échec est ben évident, on peut pu faire semblant d'pas I'voir quand on est couché en d'sous d'la boule. On a pu I'choix, on s'transforme en femme bionique, en super-woman, pis on fait éclater la grosse boule de deux tonnes.

Veux-tu ben m'dire pourquoi on attend d'être en-d'sous d'la boule? Ca s'rait ben plus simple quand c'est encore nous autres qui est d'sus, y m'semble!

Si on pouvait en parler de c't'échec là! Mais on ose pas. On peut pas, parce que de toutes façons, aussitôt qu'on ouvre la bouche, on est coupable. Peu importe c'qu'on a fait, ça aura pas été correct ou ça aura pas été assez.

"Une bonne femme, ça sait t'nir son homme".

On a tu été assez programmées, manipulées! On sait même pu si, c'qu'on fait, ça vient d'nous autres. Moé, j'ai toujours un doute à chaque geste que j'pose. J'sais jamais si ça vient pas d'ma carte d'ordinateur qui m'passe bord en bord d'la tête, ousqu'y a été perforé mon beau rôle de sainte femme idéale.

Bonne, dévouée, patiente, discrète, obéissante et docile, conciliante et souriante, C.O.M.P.R.É.H.E.N.S.I.V.E. et muette. Pas trop mince, pas trop grosse, pas trop grande, pas trop p'tite, réservée pour les étrangers, ben cochonne pour son homme. Les ch'veux tirés, ben attachés, pour magasiner, jusqu'aux fesses pis ben crêpés pour s'faire fourrer. Ange, démon, l'exemplaire Donalda pis la fameuse Nana en même temps.

De tout pour tous les fantasmes!

C'est, au moins, ça une bonne femme. 
Y va tu falloir se péter la tête contre les murs encore longtemps, pour la faire tomber c'te maudite carte là?.........

Des fois, je r'garde par la f'nêtre d'la cuisine, pis j'imagine toutes les femmes assises dans leur cuisine, en train d'écrire le livre de leur vie. Ça f'rait une belle collection, Les comptes des mille et une vies.

Leur planète bleue (parce que c'est la leur) en prendrait un coup, a s'arrêterait ben d'virer. Toutes les femmes assises dans leur cuisine, pour rien faire d'autre que d'écrire jours et nuits. Maudit, ça prendrait ben ça!

Mon Dieu, qu'chu fatiquée! Ça s'peut pas fatiquée d'même autant dans son corps que dans son âme.

Ben non, voyons, j'peux pas être fatiquée. J'peux me I'ver toute la nuit pour les p'tits, pis ben d'bonne heure le matin parce qu'y ont faim, c'est pas grave, j'fais rien d'mes grandes journées, j'travaille pas moé ...

Y me l'a dit: "T'es qui toé? T'es personne, tu gagnes rien, t'es rien toé." Y me l'a dit. J'aurais ben pu y crier que j'étais Isabelle aux ailes cassées pis que j'fesais rouler la société, mais j'ai rien dit. J'ai pas fait ma valise, chu pas partie, comme j'm'étais promis que j'f'rais à la moindre $p^{\prime}$ tite saute d'humeur.

Des p'tites sautes d'humeur, pis des grosses, pis pu d'humeur pantoute, ça m'a passé su l'corps, pis j'ai rien dit. On s'en fait tu accroire au nom d'l'espoir!

Ouais, y'est encore sorti. A l'heure qu'y' est là, y viendra pu coucher. Mais ça fait pu rien, parce que j'ai presque fini d'coudre la super lettre de lumière sur mon super costume. Pis $j^{\prime} \mathrm{m}^{\prime}$ en va I'mettre. Pis, une fois qu'ça va être faite, y aura pu personne pour me l'enlever, mon beau costume avec la super lettre.

E. E., pour échec, pour écoeurez-moé. Pis E, pour Enfin, Effervescence. Un super E pour une super Envolée.

E. ECCE FEMINA! 


\section{BOUQUET DE LUMIÈRE}

La lumière envahit doucement un petit bouquet de fleurs blanches posé sur une commode. Et la lumière joue et la lumière rit, caressant ici le contour d'un pétale, glissant là, entre les tiges, parmi les ombres enchevêtrées.

De ce mariage de lumière et de fleurs, naît un paysage magique qui m'emporte. Et j'imagine un sous-bois enchanté où de petits sentiers mènent en un lieu féérique.

En ce samedi après-midi, où le temps est à la rêverie et où mon âme est en paix, je regarde, sur une commode, un petit bouquet de fleurs blanches que la lumière a envahi avec douceur.

Et je trouve cela beau! 